\title{
HUBUNGAN SELF-RATED ORAL HEALTH TERHADAP INDEKS KUNJUNGAN RUTIN PEMERIKSAAN KESEHATAN GIGI DAN MULUT KE DOKTER GIGI
}

Dyah Nawang Palupi Pratamawari ${ }^{*}$ Ahmad Marwan Hadid ${ }^{*}$

Keywords:

Self-Rated Oral

Health, Routine

Dental Checkup

\section{ABSTRACT}

Background: Self-Rated Oral Health $(\mathrm{SROH})$ is a simple measurement of the general condition of oral health based on self-assessment. SROH is an important key that has an impact on welfare and quality of life. This study aims to determine the relationship between $\mathrm{SROH}$ and the routine dental visit every six months.

Method: Using a cross-sectional data collected from the population of the FKG UB students, there are 97 students that have been surveyed as respondents. This research was taken with questionnaire of $\mathrm{SROH}$ and information about doing dental checkup was obtained.

Results: Self-Rated Oral Health (SROH) of the student on average is sufficient (51.6\%). FKG UB students who routinely do a dental visit are $30.9 \%$. Respondents with good Self-Rated Oral Health have a higher percentage for a routine dental checkup (RDCU). Based on the Pearson Correlation Test, the study found that the $\mathrm{SROH}$ and RDCU relationship has a significant relationship $(p>0.05)$.

Conclusion: There is a significant relationship between Self-Rated Oral Health students with a dental visit every six months

\section{PENDAHULUAN}

Motivasi setiap individu untuk melakukan kunjungan ke dokter gigi secara rutin masih sangat perlu untuk diketahui, khususnya dalam upaya memberikan kesadaran kepada masyarakat tentang pentingnya pemeriksaan secara mandiri tentang kesehatan gigi dan mulut. Hal ini didukung dengan kenyataan bahwa penduduk Indonesia yang mendapat perawatan gigi dan mulut saat mengalami masalah gigi dan mulut masih relatif rendah, yakni hanya $31,1 \%$ yang dapat memperoleh perawatan dan pengobatan dari tenaga medis kesehatan gigi dan mulut ${ }^{1}$. Menurut penelitian yang dilakukan Maharani, tingkat kebutuhan masyarakat Indonesia akan kesehatan gigi dan mulut hanya sebesar $2,28 \%$. Bahkan yang menggunakan layanan kesehatan gigi hanya $0,74 \%{ }^{2}$

Self-Rated Oral Health (SROH) atau indikator penilaian secara mandiri terhadap kes- ehatan gigi dan mulut adalah sebuah cara sederhana untuk melihat persepsi setiap diri seseorang tentang kesehatan gigi dan mulutnya ${ }^{3}$. Angka penilaian ini sangat bermanfaat dalam mengukur kesehatan setiap individu dan masyarakat secara umum dan telah dipergunakan oleh beberapa studi epidemiologi, yaitu untuk memprediksi kondisi kesehatan yang akan datang ${ }^{4}$. WHO menyatakan bahwa informasi $\mathrm{SROH}$ yang diperoleh dipergunakan untuk mengidentifikasi pendekatan yang tepat dalam rangka menyusun rencana strategi dan pelaksanaan program kesehatan masyarakat ${ }^{5}$. $\mathrm{SROH}$ dapat dengan mudah dipergunakan oleh karena pertanyaan dalam $\mathrm{SROH}$ sederhana dan mudah dipahami ${ }^{6}$.

Secara umum, indikator penilaian $\mathrm{SROH}$ meliputi pemeriksaan tentang faktor keadaan klinis gigi, faktor subyektif dan faktor sosial. Faktor keadaan klinis meliputi kerusakan gigi, gigi yang hilang, dan gusi berdarah, sementara faktor subyektif adalah terkait dengan laporan 
kondisi kesehatan secara umum dan kondisi adanya nyeri di mulut. Sedangkan, faktor sosial meliputi tingkat stres, tingkat pendidikan, dan tingkat ekonomi ${ }^{3,7}$. Selanjutnya, kunjungan atau pemeriksaan berkala ke dokter gigi (routine dental checkup=RDCU) juga merupakan salah satu faktor dalam penilaian $\mathrm{SRO}^{5}$. Ketika informasi kunjungan ke dokter gigi dipengaruhi oleh dukungan sosial dari salah satu anggota keluarga atau teman, dan faktor keuangan?, maka variabel kunjungan ke dokter gigi akan menjadi faktor penentu bagi masyarakat dalam menjaga kesehatan gigi dan mulut.

Beberapa penelitian terdahulu tentang SROH telah membuktikan bahwa faktor-faktor gejala subjektif, perilaku kesehatan mulut dan kondisi klinis ${ }^{8,9,10}$ memiliki hubungan dan pengaruh yang signifikan terhadap $\mathrm{SROH}$. Studi Djemal, et al. ${ }^{10}$ menyimpulkan bahwa terdapat kurangnya persepsi tentang perlunya perawatan gigi oleh sebagian besar pasien dialisis ginjal, sehingga setiap upaya untuk meningkatkan kesadaran dan pentingnya kesehatan mulut dan gigi yang baik harus dilakukan.

Berdasarkan latar belakang ini, maka perlu diketahui hubungan antara $\mathrm{SROH}$ dengan indeks kunjungan rutin untuk pemeriksaan gigi dan mulut (routine dental checkup=RDCU) agar dapat menggambarkan secara empirik bagaimana persepsi diri mahasiswa fakultas kedokteran gigi Universitas Brawijaya (FKGUB) atas kesehatan gigi dan mulutnya terhadap motivasi mereka untuk melakukan pemeriksaan gigi dan mulut secara berkala ke dokter gigi.

\section{METODE PENELITIAN}

Penelitian ini menggunakan analitik observasional dengan pendekatan cross sectional. Setiap subyek penelitian mendapat perlakuan satu kali. Semua subyek penelitian diamati pada waktu yang sama. Penelitian ini menggunakan teknik total sampling, dengan cara menjadikan semua populasi sebagai sampel. Populasi responden adalah mahasiswa Fakultas Kedokteran Gigi Universitas Brawijaya angkatan 2017 sejumlah 97 orang. Subyek diberi kuesioner $\mathrm{SROH}$, kuesioner tentang perawatan dirinya dan kemudian dilakukan pemeriksaan klinis rongga mulut. Kuesioner $\mathrm{SROH}$ berisikan pertanyaan tentang persepsi diri terhadap kondisi kesehatan gigi, seperti tabel berikut:

Tabel.1 Form SROH

\begin{tabular}{|l|l|}
\hline In general, would you say your health \\
is: (chose one) \\
Gery good \\
Food
\end{tabular}

(dikutip dari Stanford Patient Education Research Center; www.selfmanagementresource.com/docs/ pdfs/generalhealth.pdf)

Pertanyaan tentang perawatan gigi diantaranya berisi kontrol rutin ke dokter gigi, pola menyikat gigi, perawatan pencegahan yang pernah diterima. Kontrol rutin ke dokter gigi tidak membedakan subyek datang dalam kondisi sakit maupun sehat. Kontrol rutin yang dimaksud adalah kontrol ke dokter gigi dua kali dalam setahun, tidak dibedakan untuk pemeriksaan maupun tindakan. Pola menyikat gigi adalah frekwensi dalam sehari. Perawatan pencegahan yang dimaksud adalah melakukan aplikasi topikal fluoride. 
Sebelum penelitian dimulai, seluruh subyek yang telah bersedia dan memenuhi kriteria diminta untuk mengisi informed consent dan dijelaskan tentang prosedur penelitian. Pemeriksaan indeks DMF-T dilakukan oleh dokter gigi menggunakan kaca mulut dan periodontal probe (probe WHO) steril dengan dibantu oleh mahasiswa sebagai asisten. Pembagian kuesioner dilakukan oleh peneliti setelah subyek mengisi informed consent. Hasil pengisian kuesioner $\mathrm{SROH}$ dan kontrol rutin dihitung nilainya dan direkapitulasi bersama dengan hasil pemeriksaan klinis DMF-T.

Penelitian ini telah melalui ethical clearance dari Komisi Etik Penelitian Kesehatan Fakultas Kedokteran Universitas Brawijaya nomer 117/ EC/KEPK-S1/05/2018.

\section{HASIL PENELITIAN}

Dalam penelitian ini subyek mendapat dua tahap perlakuan, yang pertama ialah pengisian kuesioner dan kemudian dilanjutkan dengan pemeriksaan klinis rongga mulut.

Jumlah subjek yang diteliti dalam penelitian ini sebanyak 97 responden dengan rincian laki-laki sebesar $11,3 \%(n=11)$ dan wanita $88,7 \%$ $(\mathrm{n}=86)$. Subyek yang berasal dari kota Malang sejumlah $23,7 \% \quad(n=23)$ orang dan sisanya $74 \%(n=74)$ mahasiswa berasal dari luar kota Malang. Untuk subyek yang melakukan kon- trol rutin ke dokter gigi 2 (dua) kali setahun sejumlah 30,9\% $(n=30)$ orang dan yang tidak kontrol rutin sejumlah $67,1 \%(n=67)$.

Dari hasil pengisian kuesioner $\mathrm{SROH}$ diperoleh hasil subyek yang memiliki persepsi diri tentang kesehatan gigi dan mulutnya yang sangat baik sejumlah $3,1 \%(n=3)$, baik $34 \%$ $(n=33)$, cukup $51,6 \%(n=50)$, kurang $11,3 \%$ $(n=11)$ serta yang menilai buruk tidak ada $(0 \%)$.

Subyek yang melakukan kunjungan rutin ke dokter gigi setahun dua kali dalam satu tahun dan mempunyai skor DMF-T yang sangat rendah sebesar 56,5\% (n=13); skor rendah $35 \%(n=7)$, sedang $27,8 \%(n=10)$ tinggi $0 \%$ dan sangat tinggi $0 \%$. Subyek yang melakukan kunjungan rutin ke dokter gigi setahun dua (2) kali dan mempunyai kebiasaan menyikat gigi satu (1) kali sehari sebesar $0 \%$, menyikat gigi dua (2) kali sehari 28,9\% ( $n=26)$ dan menyikat gigi tiga (3) kali sehari $57,1 \%(n=4)$. Subyek yang melakukan kontrol setahun dua (2) kali dan sudah mendapat perawatan dengan apikasi fluor sebesar $21,4 \%(n=3)$, sedangkan yang belum $32,5 \%(n=27)$. Subyek yang melakukan kontrol rutin ke dokter gigi yang berasal dari kota Malang (kota asal) sebesar $17,4 \%(n=4)$ dan yang tidak melakukankontrol rutin namun berasal dari kota Malang sebesar $82,6 \%(n=19)$. Responden yang rutin ke dokter gigi dan tidak berasal dari kota Malang sebesar 35,1\% ( $n=26)$. Sedangkan yang tidak

Tabel 2. Tabel Self-Rated Oral Health pada mahasiswa Fakultas Kedokteran Gigi Univ. Brawijaya

\begin{tabular}{ccc}
\hline SROH & Frekuensi & Persentase (\%) \\
\hline Sangat Baik & 3 & $3.1 \%$ \\
Baik & 33 & $34.0 \%$ \\
Cukup & 50 & $51.6 \%$ \\
Kurang & 11 & $11.3 \%$ \\
Buruk & 0 & $0.0 \%$ \\
Total & 97 & $100.0 \%$ \\
\end{tabular}


rutin ke dokter gigi dan berasal dari luar kota Malang sebesar 64,9\% ( $n=48)$. Subyek yang melakukan kontrol rutin ke dokter gigi dan menyikat giginya sehari 2 (dua) kali sebesar $28,9 \%(n=26)$ dan yang tidak kontrol rutin dan menyikat giginya dua (2) kali sehari sebesar $71,1 \%(n=64)$.

\section{DISKUSI}

Self-Rated Oral Health (SROH) merupakan sebuah pengukuran sederhana mengenai kondisi umum kesehatan rongga mulut berdasarkan penilaian mandiri. Pertanyaan Self-Rated Oral Health sengaja dibuat samar untuk melihat penilaian kesehatan masyarakat menurut definisi mereka sendiri. Meskipun jawaban atas Self-Rated Oral Health dinilai didasarkan pada apa yang mereka pikirkan dan penilaiannya bersifat subjektif, penilaian ini berdasarkan statistik dinilai bagus dalam memprediksi kondisi kesehatan gigi dan mulut dalam populasi secara umum ${ }^{6}$.

Stanford Patient Education Research Center memiliki form dan skala penilaian yang sudah digunakan dalam National Health Interview Survey. Form ini berisi persepsi diri dengan poin 5 untuk "buruk", 4 untuk "kurang baik", 3 untuk "sedang", 2 untuk "baik" dan 1 untuk "sangat baik". Penilaian ini hanya dihitung satu poin saja. Skor yang lebih tinggi menunjukkan kesehatan yang lebih buruk. $\mathrm{SROH}$ dipengaruhi oleh gejala subjektif dari stomatitis, TMJ, perilaku kesehatan gigi dan mulut, skor DMFT dan maloklusi ${ }^{6}$.

Hasil penelitian menunjukkan bahwa mahasiswa Fakultas Kedokteran Gigi Universitas Brawijaya (FKG UB) sebagian besar $(51,6 \%)$ menilai dirinya dengan memiliki skor $\mathrm{SROH}$ "cukup" dan 34\% menilai dirinya "baik". Responden merasa bahwa tidak terdapat mas- alah pada TMJ, perilaku maupun klinis giginya (karies, stomatitis dan maloklusi). Hasil yang baik ini dapat dipergunakan untuk memperkirakan kualitas hidup. Mahasiswa FKG UB merasa bahwa saat ini dengan kondisi kesehatan gigi dan mulutnya baik, bermakna bahwa pada kondisi saat ini kualitas hidup mahasiswa FKG UB dalam keadaan baik.

Kunjungan rutin ke dokter gigi telah diteliti sejak bertahun-tahun yang lalu. Kunjungan rutin ke dokter gigi mempunyai korelasi yang sangat erat dengan perilaku sehari-hari seseorang dalam menjaga kesehatan gigi dan mulutnya. Seseorang yang rajin berkunjung ke dokter gigi mempunyai korelasi erat dengan angka kejadian karies. Makin tinggi angka kunjungan ke dokter gigi maka makin baik kondisi gigi geliginya. Orang yang tidak datang ke dokter gigi makin buruk kondisi rongga mulutnya ${ }^{11}$.

Pada umumnya orang tidak berkunjung ke dokter gigi oleh karena merasa bahwa kunjungan ke dokter gigi bukan suatu kewajiban. Sebagian besar keengganan berkunjung ke dokter gigi karena alasan biaya dan karena takut (anxiety) ${ }^{12,13}$. Dari penelitian yang dilakukan oleh Hill tahun 2013, SROH terkait erat dengan faktor sosioekonomi. Makin rendah tingkat sosial ekonominya, makin tinggi angka kejadian kariesnya ${ }^{13}$.

Masyarakat merasa bahwa kontrol ke dokter gigi hanya diperlukan bila masalah timbul seperti gigi yang sakit ataupun keadaan yang darurat (sakit yang tak kunjung reda maupun oleh karena terkena trauma). Masyarakat masih cukup jarang yang melakukan kontrol rutin ke dokter gigi bila belum merasa sangat terganggu. Bila dihubungkan dengan kunjungan ke dokter gigi tampak bahwa mahasiswa yang mempunyai skor DMFT "sangat rendah" cenderung untuk rutin kontrol ke dokter gigi. Hal ini berhubungan dengan persepsi diri pada 
Tabel 3. Tabulasi silang kontrol rutin dengan skor DMF-T, jenis kelamin, asal mahasiswa, aplikasi fluor dan menyikat gigi

\begin{tabular}{llllll}
\hline & \multicolumn{4}{c}{ Kontrol Rutin } & Total \\
\hline & \multicolumn{4}{c}{ Ya } & \multicolumn{2}{c}{ Tidak } & \\
\hline DMF-T: & & & & & \\
Sangat rendah & 13 & $(56.5 \%)$ & 10 & $(43.5 \%)$ & 23 \\
Rendah & 7 & $(35.0 \%)$ & 13 & $(65.0 \%)$ & 20 \\
Sedang & 10 & $(27.8 \%)$ & 26 & $(72.2 \%)$ & 36 \\
Tinggi & 0 & $(0.0 \%)$ & 13 & $(100.0 \%)$ & 13 \\
Sangat tinggi & 0 & $(0.0 \%)$ & 5 & $(100.0 \%)$ & 5 \\
\hline Jenis Kelamin: & & & & & \\
L & 3 & $(27.3 \%)$ & 8 & $(72.7 \%)$ & 11 \\
P & 27 & $(31.4 \%)$ & 59 & $(68.6 \%)$ & 86 \\
\hline Asal: & & & & & \\
Malang & 4 & $(17.4 \%)$ & 19 & $(82.6 \%)$ & 23 \\
Luar Malang & 26 & $(35.1 \%)$ & 48 & $(64.9 \%)$ & 74 \\
\hline Aplikasi Fluor: & & & & & \\
Sudah & 3 & $(21.4 \%)$ & 11 & $(78.6 \%)$ & 14 \\
Belum & 27 & $(32.5 \%)$ & 56 & $(67.5 \%)$ & 83 \\
\hline Menyikat gigi: (hari) & & & & & \\
1x & 0 & $(0.0 \%)$ & 0 & $(0.0 \%)$ & 0 \\
2x & 26 & $(28.9 \%)$ & 64 & $(71.1 \%)$ & 90 \\
$3 x$ & 4 & $(57.1 \%)$ & 3 & $(42.9 \%)$ & 7 \\
\hline
\end{tabular}

responden. Untuk responden yang merasa bahwa dirinya "cukup" maka cenderung untuk mencari solusi atas masalah kesehatan giginya, sehingga rutin melakukan kunjungan ke dokter gigi. Hal ini sejalan dengan yang ditemukan pada penelitian Afonso-Souza (2007) bahwa makin rendah skor SROH maka makin rendah pula kontrol rutin ke dokter gigi ${ }^{11}$. Bila seseorang merasa bermasalah dalam kondisi rongga mulutnya maka kunjungan ke dokter gigi makin tinggi.

Ostberg menyebutkan bahwa terdapat perbedaan persepsi pada gender yang berbeda, di mana wanita merasa lebih baik dibandingkan dengan persepsi laki-laki. Responden wanita mengungkapkan persepsi dirinya dalam kondisi "cukup" $(48,8 \%)$ dan "baik" $(34,9 \%)$. Sedangkan pada laki-laki melihat dirinya dengan skor "cukup" (72,7\%). Berdasarkan faktor psikologis, wanita cenderung mengungkapkan bah- wa dirinya "cukup sehat", bahkan "baik". Hal ini sejalan dengan studi yang dilakukan oleh Ostberg yang menyimpulkan bahwa terdapat perbedaan persepsi pada gender berbeda ${ }^{14}$.

\section{KESIMPULAN}

Dari penelitian ini dapat disimpulkan bahwa: Makin baik persepsi seseorang terhadap kesehatan gigi dan mulutnya maka makin rutin untuk melakukan kontrol ke dokter gigi. Dari pemeriksaan klinis disimpulkan pula bahwa makin baik persepsi seseorang terhadap kesehatan gigi dan mulutnya maka makin rendah angka kejadian kariesnya.

\section{DAFTAR PUSTAKA}

1. Badan Penelitian Dan Pengembangan Kesehatan Kementerian Kesehatan RI. Riset Kesehatan Dasar 2013. Kementrian Kesehatan Republik In- 
donesia. 2013.

2. Maharani DA, Rahardjo A. Is the utilisation of dental care based on need or socioeconomic status? A study of dental care in Indonesia from 1999 to 2009. Int Dent J [Internet]. 2012 Apr 1 [cited 2019 Mar 25];62(2):90-4. Available from: http://doi.wiley.com/10.1111/j.1875-595X.2011.00095.x

3. Pattussi MP, Peres KG, Boing AF, Peres MA, Da Costa JSD. Self-rated oral health and associated factors in Brazilian elders. Community Dent Oral Epidemiol. 2010;

4. Benyamini $Y$, Leventhal $H$, Leventhal EA. Self-rated oral health as an independent predictor of self-rated general health, self-esteem and life satisfaction. Social Science and Medicine. 2004.

5. World Health Organization. Oral Health Surveys Basic Methofd. World Health Organization. 2013.

6. Pattussi MP, Olinto MTA, Hardy R, Sheiham A. Clinical, social and psychosocial factors associated with self-rated oral health in Brazilian adolescents. Community Dent Oral Epidemiol. 2007;

7. Finlayson TL, Williams DR, Siefert K, Jackson JS, Nowjack-Raymer R. Oral health disparities and psychosocial correlates of self-rated oral health in the national survey of american life. Am J Public Health. 2010;

8. Gironda MW, Maida C, Marcus M, Wang Y, Liu H. Social support and dental visits. J Am Dent Assoc. 2013;

9. Kojima A, Ekuni D, Mizutani S, Furuta M, Irie K, Azuma T, et al. Relationships between self-rated oral health, subjective symptoms, oral health behavior and clinical conditions in Japanese university students: a cross-sectional survey at Okayama University. BMC Oral Health [Internet]. 2013 Dec 6 [cited 2019 Mar 25];13(1):62. Available from: http://bmcoralhealth.biomedcentral. com/articles/10.1186/1472-6831-13-62
10. Djemal S, Rumjon A, Macdougall IC, Singh P, Warnakulasuriya S. Dental Attendance and Self-reported Oral Health Status of Renal Dialysis Patients: A Comparison of Results with the UK Adult Dental Health Survey. Oral Health Prev Dent [Internet]. [cited 2019 Mar 25];14(6):529_ 34. Available from: http://www.ncbi.nlm.nih.gov/ pubmed/27957563

11. Afonso-Souza G, Nadanovsky P, Chor D, Faerstein E, Werneck GL, Lopes CS. Association between routine visits for dental checkup and self-perceived oral health in an adult population in Rio de Janeiro: The Pró- Saúde study. Community Dent Oral Epidemiol. 2007;

12. Murray C, Densie IK ennet., Morgan C. Dental attendance, perceptions of cost and self-care of school year 12 and 13 students: A focus on Southland, New Zealand. N Z Dent J. 2015;

13. Hill KB, Chadwick B, Freeman R, O'Sullivan I, Murray JJ. Adult Dental Health Survey 2009: Relationships between dental attendance patterns, oral health behaviour and the current barriers to dental care. Br Dent J. 2013;

14. Ostberg AL, Halling A, Lindblad U. A gender perspective of self-perceived oral health in adolescents: associations with attitudes and behaviours. Community Dent Health [Internet]. 2001 Jun [cited 2019 Mar 25];18(2):110-6. Available from: http://www.ncbi.nlm.nih.gov/pubmed/11461058 